\title{
La invención de un género: Heródoto, Tucídides y los retos de escribir prosa histórica a gran escala ${ }^{1}$
}

\author{
Inventing a New Genre: Herodotus, Thucydides
}

and the Challenge of Writing Large-Scale Prose History

\author{
Kurt A. RAAFLAUB \\ Brown University, Providence, R. I. Estados Unidos \\ kurtraaflaub@brown.edu
}

\begin{abstract}
RESUMEN: El interés por el pasado (ya sea histórico o mítico) es tan antiguo como la literatura griega. La poesía (épica, elegía y tragedia) dramatizaba los acontecimientos del pasado. Entre los escritores en prosa, Hecateo estableció un primer estándar, pero sus obras con contenido histórico fueron más breves y simples que las de sus sucesores. Heródoto escribió la primera historia extensa y compleja de un acontecimiento histórico importante como "un relato múltiple, orientado de manera contingente" (Christian Meier), y fue pronto seguido por Tucídides. Aunque este último conoció en su momento la obra de Heródoto, pudo haberla tenido sólo después de haber comenzado a escribir su propio texto.

Los desafíos que enfrentaron estos autores al crear, establecer y legitimar un nuevo género eran formidables. Aunque tenían un lejano predecesor en la épica, en lo esencial, entraron en un territorio desconocido y tuvieron que encontrar la manera de organizar su material, presentar su relato y atraer la atención de su público. En un mundo profundamente fragmentado, con tradiciones y recuerdos contradictorios, eligieron escribir desde una perspectiva panhelénica (o aún más amplia), por lo que tuvieron que crear su propio público. Aunque eran diferentes en edad y antecedentes, eran contemporáneos y participaban en el ambiente competitivo y en la vibrante cultura intelectual de su tiempo. Cabría esperar, en con-
\end{abstract}

${ }^{1}$ Agradezco ante todo a la profesora Martha Elena Montemayor y a sus compañeros del comité organizador por invitarme a presentar una conferencia magistral en el Tercer Congreso Internacional de Estudios Clásicos en México, y por su generosa hospitalidad. Agradezco en especial a los estudiantes (particularmente a Ruth y a Cecilia) que contribuyeron de forma imprescindible a la organización intachable del congreso y ayudaron infatigablemente a los participantes. También agradezco a Deborah Boedeker y Jonas Grethlein sus valiosos comentarios sobre las versiones anteriores de este trabajo, a Carolyn Dewald por las discusiones estimulantes sobre la materia de la que trata, a los participantes de este congreso, al igual que a aquellos de congresos anteriores en Atenas y Moscú, por sus útiles preguntas y sugerencias, y a Felipe Valencia por la traducción de este artículo al español. Presenté una versión anterior de este capítulo en las Lecturas Gasparov en la Universidad Estatal de Humanidades de Moscú. Se publicará en las actas de aquel congreso. Les agradezco a los editores de ambos volúmenes el haberse puesto de acuerdo para realizar la publicación simultánea en español y en ruso. Dedico este capítulo a la memoria de Paola Vianello, que murió mucho antes de su tiempo el 25 de enero de 2007. La conocí en el Primer Congreso en México hace seis años y encontré inspiradora su pasión por las cuestiones e intereses que compartimos. 
secuencia, que, a pesar de sus diferencias de enfoque, metodología, estilo y visión del mundo, podían también compartir algunas de las soluciones a los desafíos que ambos enfrentaban.

Este artículo discutirá algunas técnicas semejantes que los dos autores desarrollaron para hacer sus historias importantes, interesantes y significativas para sus lectores. Algunas de estas técnicas (por ejemplo, la combinación de narración y discursos) las tomaron de la épica. Otras eran mecanismos nuevos y altamente originales para estructurar la narración, insertar indicaciones para llamar la atención de los lectores sobre aspectos importantes, involucrarlos en la acción narrada $\mathrm{u}$ ofrecer patrones que comprometen a los lectores a una interacción dinámica entre el pasado y el presente.

ABSTRACT: Interest in the past (whether historical or mythical) is as old as Greek literature. Poetry (epic, elegy, and tragedy) dramatized past events. Among prose authors, Hecataeus set an early standard, but his works with historical content were shorter and simpler than those of his successors. Thus, it was Herodotus who wrote the first large-scale and complex history of an important historical event as "a multi-subjective, contingency-oriented account" (Christian Meier). Such work was soon to be followed by Thucydides. Although the latter eventually knew Herodotus' work, he may have encountered it only after he had started to write his own.

The challenges these authors faced in creating, establishing, and legitimizing a new genre were formidable. Although they found a distant predecessor in the Epics, they essentially entered uncharted territory. Therefore, they had to figure out how to organize their material, present their narrative, and create their own audiences. In a deeply fragmented world with conflicting traditions and memories, they chose to write from a panhellenic (or even larger) perspective. Although differing in age and background, they were contemporaries, participating in the competitive environment and vibrant intellectual culture of their time. One might expect, therefore, that despite their differences in approach, methodology, style, and world view, they might also share some of the solutions to the challenges they both faced.

Thus, this paper will discuss some of the similar techniques the two authors developed to make their histories relevant, interesting, and meaningful to their readers. Some of these techniques (for instance, the combination of narrative and speeches) they borrowed from the Epics. Others were new and highly original devices to structure the narrative, insert pointers alerting the readers to important aspects, involve them in the narrated action, or draw out patterns that engaged the readers in a dynamic interaction between past and present.

PAlabRas Clave: historiografía clásica, Heródoto, Tucídides, estrategias narrativas.

KEYwords: classical historiography, Herodotus, Thucydides, narrative strategies.

RECIBIDO: 30 de enero de 2013 - ACEPTADO: 22 de agosto de 2013. 
En memoria

de Paola Vianello

En su conocida discusión sobre poesía que es perjudicial al no ser veraz, Platón comienza con la cuestión de la falsedad de las palabras. Esta falsedad es no menos evidente en los relatos sobre el pasado ( $m y$ thologiai). Como no sabemos cuál es la verdad en los relatos sobre los hechos antiguos (ta palaia), "los hacemos tan útiles como sea posible al asemejar la falsedad a la verdad". Sin lugar a dudas, Platón piensa principalmente en el mito (mythologiai), pero en el pensamiento griego no se hace una distinción tajante entre el mito y la historia, y Heródoto y Tucídides también observan que es difícil o imposible saber con certeza cualquier dato de la historia más allá de un pasado más bien reciente. ${ }^{2}$ Más aún, sostiene Platón, en los relatos sobre el pasado, que la verdad se asemeja a la falsedad ipara que sea útil! Aquí tomaré el paso - aunque es justo reconocer su riesgo - de aplicar esta afirmación a la reconstrucción de la historia. Sea cual sea la interpretación de las afirmaciones polémicas de Platón acerca de la poesía y la historia - y éste definitivamente no es el tema de este ensayo-, las utilizo como punto de partida para mi indagación.

Mi pregunta principal es ¿por qué el pasado -o la historia- necesita la falsedad $-\mathrm{o}$, forzando la traducción, la ficción - ? ¿Y por qué la historia ha de ser útil para empezar? Esto me conduce a una serie aún mayor de preguntas. Sin importar lo que escribieron sus predecesores, sobre los cuales lamentablemente se sabe poco, ${ }^{3}$ podemos afirmar que Heródoto y Tucídides produjeron las primeras historias complejas a gran escala sobre acontecimientos históricos importantes (fueran recientes o remotos), las cuales Christian Meier define como "versiones multi-subjetivas, orientadas a lo contingente". ${ }^{4}$ Los retos a los que se enfrentaron estos autores para crear, establecer y legitimar un género nuevo fueron formidables. Aunque se inspiraron de varias maneras en un modelo distante,

2 Th. 1.1.3; Hdt. 1.5.3; Pl. R. 2.382c-d. Agradezco a Kathryn Morgan el haberme señalado este pasaje. Para una discusión esclarecedora sobre la afirmación de Platón, véase Gill 1993, sobre todo, pp. 52-56. Sobre mito e historia, véanse Marincola 1997, pp. 117-127 y Saïd 2007.

${ }^{3}$ Véanse por ejemplo Fowler 1996 y Corcella 2006.

${ }^{4}$ Meier, 1987, pp. 44. 
el de la épica homérica, ${ }^{5}$ para todos los efectos fueron pioneros y tuvieron que descubrir modos de organizar su materia, presentar su narración y captar la atención de su público. De hecho, como veremos, tuvieron que crearlos también a éstos. Aunque distintos en edad y procedencia, ambos participaron en la floreciente y competitiva cultura intelectual de su época. Es de esperar, por lo tanto, que a pesar de las diferencias en sus acercamientos, metodologías, estilos y cosmovisiones, ambos compartieran algunas de la soluciones a los retos a los cuales se enfrentaron. Discutiré algunas correspondencias importantes entre los dos autores: una (el uso de patrones) con algún detalle; el resto, con más brevedad.

Recordemos primero sus respectivas épocas y relaciones. Sabemos que Heródoto pasó tiempo en Atenas, pero no sabemos cuándo, ni por cuánto tiempo, ni con qué frecuencia. Consta que presentó algunos de sus logoi en conferencias públicas y que se le honró y premió por ello. Charles Fornara ha sugerido, de forma plausible, que las alusiones a acontecimientos contemporáneos en su obra llegan no sólo hasta el año 430 , como se piensa generalmente, sino hasta finales de la década siguiente. Por los tanto, siguió en activo hasta alrededor del 420, si es que no más tarde, y fue testigo de la Guerra Arquidámica en su totalidad. ${ }^{6}$ Tucídides participó activamente al principio de la guerra del Peloponeso, pero salió al exilio en 424. Después de la guerra, es posible que volviera a Atenas; se supone que murió a principios del siglo IV. Según sus propias afirmaciones, empezó a recoger materiales y posiblemente a esbozar su narración desde el principio mismo de la guerra, continuó su trabajo durante ella y, como atestiguan observaciones posteriores, revisó las primeras partes después del final de la guerra. ${ }^{7}$ Por lo tanto, aunque

${ }^{5}$ Sobre los historiadores y Homero, véanse Strasburger 1972; Hartog 2000; Boedeker 2002; Marincola 2006, y Pelling 2006a. Sobre los orígines de la historiografía griega, véanse Meier 1973, 1987; Boedeker 1998, y Darbo-Peschanski 2007. Sobre la historiografía en general, véase Assmann y Müller 2005. Para la historiografía como un género nuevo, véanse Dewald 1985, p. 47; Lateiner 1989, capítulo 1, y Corcella 2006, todos con referencias.

${ }^{6}$ Fornara 1971a, 1981. Para un resumen de la discusión acerca de la datación de la obra de Heródoto, véase Raaflaub 2002a, pp. 36-37. Sobre Heródoto y Atenas, véanse Fornara 1971b, pp. 37-58; Ostwald 1991; Moles 1996, 2002; Fowler 2003, y Evans 2006.

${ }^{7}$ Sobre las fechas de la vida de Tucídides, véanse Hornblower 1987, pp. 1-4; Canfora 2006. Sobre la fecha de su nacimiento, Fornara 1993. Flory 1993 mantiene que la fecha de su muerte fue más tardía. Las afirmaciones del propio Tucídides se hallan en 1.1 y 5.26; y para observaciones posteriores, e. g. 2.65.11-13. Revisión de Romilly 1963. 
los dos autores pertenecían a dos generaciones distintas, sus vidas coincidieron de manera considerable y, lo que es más importante, coincidieron sus actividades como historiadores, cronológica y geográficamente. Con el tiempo Tucídides llegó a conocer la obra de Heródoto y entabló con ella un diálogo en un discurso intertextual crítico y competitivo; ${ }^{8}$ es bien probable que lo conociera y oyera en persona. ¿Qué habría ocurrido si hablaran y discutieran los problemas de escribir un nuevo tipo de historia? La idea es intrigante y tal vez menos inverosímil de lo que se podría pensar.

Paso ahora a abordar la ficción. El término implica unas connotaciones modernas específicas, y su aplicación a la historiografía antigua es especialmente problemática; pero en algunos casos, no menos en Heródoto y Plutarco, es perfectamente apropiado su uso. ${ }^{9}$ Sin ir más lejos podemos pensar, por ejemplo, en el episodio final de la Historia de Heródoto: la anécdota que relata el consejo de Ciro a los persas de que no abandonaran las hostiles montañas de su patria persa a favor de las fértiles llanuras de las tierras conquistadas, a no ser que quisieran correr el riesgo de volverse blandos y a la larga perder su imperio. Esta anécdota, claramente ficticia, nos recuerda con apremio un esquema en la interpretación de la historia de Heródoto que se ha estudiado mucho: el contraste entre países pobres que crían a gente fuerte y países ricos que crían a gente blanda. La interpretación histórica se sirve así de la ficción. ${ }^{10}$

En Tucídides, la ficción es más difícil de detectar, pero ¿qué se puede decir acerca de su afirmación, en relación con los debates sicilianos de 415, de que "las masas (hoi polloi) desconocían la extensión de la isla" y la magnitud de la guerra que emprendían? ${ }^{11}$ Está claro que esto no pudo ser: los atenienses no sólo habían tenido extensas relaciones diplomáticas con los sicilianos, sino que hacía poco (de 427 a 424) habían

\footnotetext{
${ }^{8}$ Sobre la familiaridad de Tucídides con la obra de Heródoto, véase nota 52.

${ }^{9}$ Véase en especial Gill y Wiseman 1993; sobre la ficción en la historiografía, Moles 1993 (con bibliografía); en Heródoto, Fornara 1971b, pp. 35-36; y en Plutarco, Pelling 1990.

${ }^{10}$ Sobre la ficción, véase Hdt. 9.122 con Flower y Marincola 2002, ad loc.; Dewald 1997, y Welser 2009. Sobre el esquema de los países ricos y pobres, véanse e. g. Lateiner 1989, cap. 7; y Thomas 2000, cap. 4. Otro ejemplo, también muy discutido, es el "debate constitucional" (3.80-82): véanse Asheri et al. 2007, ad loc.; y más abajo la nota 65 del texto.
}

11 Th. 6.1.1. 
intervenido en Sicilia, al final con una flotilla considerable de sesenta naves. Por lo tanto, miles de ciudadanos atenienses habían pasado meses y aun años en Sicilia. Según Plutarco, "los jóvenes en las escuelas de lucha y los ancianos en las tiendas o lugares públicos de concurrencia se sentaban a trazar mapas de Sicilia o cartas de navegación del mar y de los puertos y de la costa enfrente de África". ${ }^{12}$ De nuevo, en este caso, una gran exageración, si no ficción, sirve a un propósito interpretativo: sitúa este episodio en el contexto de la crítica que hace Tucídides del conocimiento en la democracia, y lo conecta a una idea ya elaborada cuidadosamente por Heródoto: los imperialistas desaforados fracasan, en parte, porque no conocen (y no piensan que tienen que conocer) a sus enemigos, sus características y su país; recordemos al rey persa Jerjes desdeñando risueño al rey espartano Demarato cuando éste le explica por qué los espartanos en especial resistirían al vastamente superior ejército persa, por improbable que pareciera. ${ }^{13}$

¿Y qué hay de la utilidad de la historia, o más generalmente, del conocimiento del pasado? Ésta es, por cierto, una inquietud en la que ponen énfasis frecuente los pensadores chinos tempranos, inclusive Confucio, realizándose así uno de aquellos paralelos asombrosos entre los pensamientos chino y griego más o menos coetáneos. ${ }^{14}$ Como ya demuestra de muchas formas la épica de Homero, hacía largo tiempo que los griegos miraban hacia el pasado para estimular su pensamiento y extraer lecciones para el presente. ${ }^{15}$ Las tragedias existentes indican las inquietudes de los poetas acerca de los problemas que conmocionaban su sociedad y su habilidad de adaptar y elaborar los mitos antiguos para poner énfasis en

12 Plu. Nic. 20; véase Smith 2004. Para las relaciones diplomáticas, véanse Hornblower 1991-2008, III, pp. 5-6; para la primera expedición a Sicilia, véanse Lewis 1992, pp. 408-409, 413, 422; y Raaflaub 2002a, pp. 29-33.

13 Sobre la crítica del conocimiento democrático, véase Ober 1993. Para Jerjes y Demarato, Hdt. 7.104.

14 Sobre el pensamiento chino temprano acerca de la historia (en especial el de Confucio, por ejemplo Analectas 2.11 y 7.1 y 20) que considera "el pasado central a la comprensión del presente y otorga poderes a aquellos que conservan y saben leer correctamente el pasado", véanse Durrant 2014, Leung 1982 y Schwartz 1985, pp. 85-99.

15 Sobre los usos del pasado en la épica, véanse Kullmann 1999 y Grethlein 2006a. Para el pensamiento político en la poesía épica, enlazando el pasado con el presente, véanse Raaflaub 2000 y Hammer 2002. Sobre la "conciencia histórica" durante el periodo en que los poemas épicos “cristalizaron”, véase Patzek 1992. 
aspectos que inducirían a su público a pensar en estos problemas. De tal manera, el pasado trágico y el presente se conectaban en una dialéctica: las historias sobre el pasado servían para iluminar e instruir el presente, pero sólo podían cumplir este fin al ser reformados y reinterpretados a base de las experiencias e inquietudes del presente. ${ }^{16}$

Los historiadores tempranos adoptaron el mismo método; más abajo nos preguntaremos por qué. Tucídides, de una forma explícita, define el propósito de su Historia no como el de diversión placentera, sino como una "posesión permanente" (ktēma es aiei). ${ }^{17}$ La historia es útil, sostiene, porque les permite a aquellos que "quieren percibir con precisión" (es decir, comprender acontecimientos del pasado) sobrellevar mejor "los acontecimientos similares que, es de esperar, ocurrirán en el futuro". De esta manera nuestra habilidad de afrontar el futuro aumenta con base en el conocimiento del pasado. Como se cuida de enfatizar el historiador, la historia no se repite con exactitud (en acontecimientos idénticos), sino en patrones (acontecimientos similares). Si estamos familiarizados con tales patrones, los reconoceremos cuando se repitan y estaremos mejor preparados para enfrentarnos a ellos. Tucídides expresa esta idea de forma explícita en un contexto (la plaga de Atenas) que se presta especialmente bien para ilustrarla; pero su descripción de la plaga se enfoca no sólo en los síntomas físicos de la enfermedad, sino también en los de la crisis social, y su análisis de la guerra civil (stasis) en Córcira se concentra en los síntomas de la degeneración política y social. ${ }^{18}$ En este sentido, por lo tanto, la historia (el conocimiento del pasado) es útil, y es de notar que esta utilidad no se limita a un tiempo, sitio o contexto; es permanente, universal.

La historia comprende una variedad infinita de actores, acciones y acontecimientos. Por lo tanto no es obvio a primera vista cómo y por qué puede la historia cumplir la función que Tucídides le asigna. ¿Y por qué es importante tal cometido? Más aún, ¿cómo puede cumplirlo el historiador? ¿Cómo educa a sus lectores y cómo quiere que aprendan? Finalmente, ¿qué impacto tiene todo esto en la escritura de la historia y

16 Sobre pasado y presente en la tragedia, véanse por ejemplo Meier 1993; Saïd 1998; Boedeker y Raaflaub 2005, y Flaig 2013.

17 Th. 1.22.4. Véase, recientemente, Grethlein 2010, pp. 268-279. Sobre el método de Tucídides, véase Rood 2006.

${ }^{18}$ La identificación de los síntomas está en Th. 2.48; la peste, en 2.47-54; véase Thomas 2006b. Para la stasis en Córcira, 3.82-84; véase Price 2001. 
cómo afecta nuestro entendimiento y uso de semejante historia? Estas preguntas son básicas pero importantes, y esbozan un tema vasto y complejo. He de limitarme aquí a presentar el esquema de un argumento con algunos ejemplos, los cuales pueden ser ampliados más tarde. ${ }^{19}$

Hay dos condiciones para que el historiador sea capaz de cumplir con el cometido de Tucídides. Como un médico o un etnógrafo, tiene que reconocer en el caleidoscopio de los fenómenos que observa ciertos patrones que lo ayuden a discernir y categorizar estos fenómenos. Y en efecto, tanto Heródoto como Tucídides eran miembros de una élite intelectual panhelénica que incluía, entre muchos otros, a médicos, geógrafos y sofistas, con los cuales interactuaban competitivamente y compartían un fondo de ideas intensamente debatidas. ${ }^{20}$ Más aún, el historiador debe apoyarse en algo que garantice no sólo la existencia sino también la repetición de dichos patrones. La variedad infinita de la historia, incluso agrupada en patrones, ha de contener factores constantes y ha de obligar a estos patrones a repetirse. Como diría Heródoto, tiene que haber algo que haga que los eventos no se sucedan en línea recta, evolucionando, sino más bien en olas, círculos y ciclos. Para Tucídides, como sugiere Pierre Vidal-Naquet, los fenómenos no se repiten en el tiempo histórico, sino en el lógico. ${ }^{21}$ Los factores necesarios pueden estar contenidos en los actores de la historia y en los marcos sociales y políticos dentro de los cuales aquéllos actúan.

El factor que para Tucídides es decisivo en este contexto es la condición humana (to anthrōpinon). Dado que "la humanidad" es un elemento que permanece idéntico o estable, ya que "la gente es la gente", se comportará de manera similar en circunstancias similares. ${ }^{22}$ Como un antropólogo, el historiador recoge, categoriza y analiza el comportamiento humano, y así es capaz de pronosticarlo. Esto es lo que dota a la historia de un potencial predictivo y didáctico; el historiador le ofrece a sus

${ }^{19}$ Sobre el estudio, la reflexión teórica y los varios acercamientos a este tema, véase Dewald 2005, pp. 1-22, 193-203.

20 Thomas 2000, 2006a, 2006b; véanse también Finley 1942, cap. 2; Raaflaub 2002b, y Ober 2006.

${ }^{21}$ Para las olas y los círculos, Hdt. 1.5; 1.32, y 1.207. Para el tiempo lógico, véanse Vidal-Naquet 1986, p. 46 y Hornblower 1991-2008, I, p. 61.

${ }^{22}$ Sobre to anthrōpinon, e. g. 1.22.4; 1.84.4; 3.82.2. Véase de Ste. Croix 1972, p. 29 para más pasajes y un comentario; también Hornblower 1991-2008, I, p. 61 y Reinhold 1985. Sobre que "la gente es la gente", Derow 2009, p. 5. 
lectores las lecciones de la historia, que pueden ayudarlos a superar los retos futuros. Polibio lo expresa de manera explícita: la humanidad "no posee mejor guía de conducta que el conocimiento del pasado". Todos los historiadores sostienen que "el estudio de la historia es a la vez una educación, en el sentido más exacto de la palabra, y un entrenamiento para la carrera política". Tales lecciones pueden servir para propósitos bien puramente intelectuales, bien prácticos. ${ }^{23}$

En consecuencia, la tarea del historiador es destacar, en su presentación de la historia, los patrones que considere cruciales. Su pericia y su interpretación moldean así su presentación. En un nivel general, esto es una obviedad: por supuesto que todos los historiadores consciente e inconscientemente interpretan la historia desde cierta perspectiva con los valores, las experiencias y las expectativas de su época en mente. Pero los historiadores antiguos llevan tal interpretación tan lejos y con un empeño tan deliberado que hallamos - por decirlo suavemente - inusual. Tucídides enfatiza los patrones a través de importantes escenas ("set pieces”) retóricas y analíticas (de manera más conspicua en el discurso fúnebre y en la peste de Atenas, la stasis de Córcira, los debates en torno a Mitilene y Sicilia, y el diálogo de los melios), pero también a lo largo del análisis que recorre en una serie de episodios y que revela las corrientes y los desarrollos subyacentes. ${ }^{24}$ También podríamos mencionar el capítulo con el obituario de Pericles, a veces considerado un pasaje de "análisis político fundamentado" comparable al de la stasis de Córcira o a la brillante descripción del "carácter colectivo" ateniense comparado con el espartano, atribuida a los corintios, archienemigos de aquéllos. Estos retratos antitéticos, del mismo modo que los rasgos empleados en el discurso fúnebre para caracterizar a la democrática Atenas como una comunidad ideal, sirven como importantes herramientas interpretativas que reverberan por toda la obra. ${ }^{25}$ Hunter Rawlings sugiere que para es-

${ }^{23}$ Sobre el propósito didáctico de la historia, véase Plb. 1.1.1-2; cf. e. g. 3.12; 3.31 32 y 12.25a. Para los propósitos puramente intelectuales, véanse Gomme 1945, 149150; Hornblower 1991-2008, I, p. 61; para los prácticos, de Ste. Croix 1972, pp. 29-33 (con bibliografía).

${ }^{24}$ Th. 2.35-46 (discurso fúnebre); 2.47-54 (peste); 3.82-84 (stasis); 3.36-50; 6.8-26 (debates en torno a Mitilene y Sicilia); 5.84-116 (diálogo meliano). Sobre el análisis continuo, véanse infra nota 38.

${ }^{25}$ El obituario de Pericles está en 2, 65; véase Hornblower 1991-2008, I, pp. 340 y ss. (cita en p. 340). La caracterización antitética está en Th. 1.70-71. Para el discurso 
tablecer patrones recurrentes, Tucídides incluso deja que los eventos de la segunda mitad de la Historia repitan hasta cierto punto los de la primera mitad. ${ }^{26}$ Las escenas importantes han atraído la atención de la crítica; que yo sepa, los patrones no han sido analizados sistemáticamente.

El mismo énfasis en los patrones, y por las mismas razones, aparece ya en Heródoto, aunque él aplica el principio sin discutirlo de manera explícita. También recurre a escenas importantes y se fija en tendencias recurrentes. ${ }^{27}$ Por ejemplo, Heródoto impone sobre las conquistas más remotas de todos los reyes persas (de Ciro a Jerjes), e incluso a las de Creso, rey de los lidios, un patrón común que sin duda hallaría eco en las mentes de sus lectores. Todos estos reyes están dominados por una ambición sin límites y un hambre de conquista que los hace inmunes a la cautela, la razón o las advertencias, y que les permite sobrevalorar por mucho sus propias capacidades. Emprenden por tanto campañas que los obligan a atravesar grandes fronteras naturales u obstáculos (como ríos, océanos y desiertos), y a invadir países que no conocen, y que a su vez no encajan en sus esquemas sobre naturaleza y cultura. El resultado es que sufren severas derrotas y pérdidas, si no la propia vida. Echando mano de la elaboración - cuando no de la invención-, de los efectos dramáticos y de la retórica, y guiado por su interpretación política, Heródoto moldea el pasado (en este caso, los fracasos del imperialismo desaforado en la historia persa) de tal manera que pueda aportar un significado para el presente (en este caso, el problema del desaforado imperialismo de las poleis griegas; en especial, por supuesto, Atenas).

Tanto los individuos como las comunidades, aunque siempre diferentes respecto al carácter, se entregan a un comportamiento típico que echa raíces en la condición humana. Por ejemplo, los espartanos y los atenienses tienen "caracteres colectivos" diametralmente opuestos que determinan sus políticas y acciones, pero ambos reaccionan de modos

fúnebre como herramienta interpretativa, véase Grethlein 2005. Véase infra en el texto en nota 65 .

${ }^{26}$ Rawlings 1981, pp. 38-57 y Moles 1993, p. 108.

${ }^{27}$ Las escenas tipificadas en Heródoto son, por ejemplo, 1.96-100 (para el "modelo del tirano", Dewald 2003); 3.80-82 (el "debate constitucional"); 7.5-18 (el debate en la corte de Jerjes; véase Raaflaub 2002a). Para patrones que se repiten, véanse e. g. la autocracia oriental (Lateiner 1989, cap. 8); el imperialismo persa (Raaflaub 1987 y 2002a, con fuentes y bibliografía). En general, véanse Strasburger 1955, Fornara 1971b, Hunter 1982, pp. 176-225 y, sobre disposición en patrones en Heródoto, Lateiner 1989, pp. 165-167. 
semejantes cuando se enfrentan a retos parecidos. ${ }^{28} \mathrm{~A}$ nivel individual, el historiador pone cuidadoso énfasis en las distintas personalidades de cada político, pero también los incorpora a categorías tipificadas (tanto Diodoto en el debate en torno a Mitilene, como Nicias en el siciliano presentan rasgos destacados en el retrato de Pericles). En sus funciones como líderes atenienses o espartanos, estos políticos persiguen fines similares (como la seguridad y la grandeza ateniense o la protección de los intereses de Esparta), aun si defienden prioridades distintas y estrategias divergentes para alcanzar sus objetivos. Tal semejanza en las reacciones se debe al susodicho marco sociopolítico; por ejemplo, las comunidades y sus constituciones políticas; rivalidad, guerra e imperio; condiciones y recursos materiales, e ideas e ideologías. Estos factores, sumados al elemento común que es la condición humana (to anthrōpinon), fijan los parámetros dentro de los cuales se desarrollan los patrones que el historiador discierne en la historia y desarrolla en su narración.

En nuestro examen de los patrones de la Historia de Tucídides nos enfrentamos a un gran obstáculo: la obra está incompleta, y no sabemos cómo interpretó el autor las etapas finales de la guerra. ${ }^{29}$ Pero sí vio el final de la guerra, y usó este conocimiento del resultado para enfocar con una luz particular pasajes anteriores. La perspectiva posterior también se presta a la tarea de disposición en patrones. Por ejemplo, sabemos gracias al propio Tucídides y a Jenofonte que en las políticas espartanas el predominio del interés propio a costa de los aliados quedó de manifiesto en la Paz de Nicias y más todavía en la Guerra Jónica. ${ }^{30}$ Pero incluso antes de la guerra, Tucídides deja que los aliados expresen dudas acerca de la sinceridad de la preocupación de Esparta por los intereses comunes, y que la acusen de tolerar su "esclavización" por parte de Atenas. Más aún, según su exposición, los atenienses sostienen no sólo en 416 en Melos, sino incluso antes, en 432 en Esparta, que los espartanos habrían

${ }^{28}$ Para los caracteres colectivos, véase supra nota 25; para la reacción similar de ambas poleis, Hdt. 1.76 y 5.105.

${ }^{29}$ Véase Canfora 2006, pp. 20-26 sobre la posibilidad de que los apuntes de Tucídides fuesen preservados, y que en base a ellos elaborase Jenofonte algunos segmentos de los dos primeros libros de sus Helénicas. Flory 1993 sugiere que Tucídides no quiso terminar su obra.

${ }^{30}$ Sobre las políticas de interés propio de Esparta, Th. 5.17 y ss. (Paz de Nicias; véase Lendon 2010, pp. 323-367) y X. HG. 1.1.2-3 (Guerra Jónica; sobre la formación del imperio espartano, Cartledge 1987). 
tratado a sus aliados de la misma manera que habían hecho los atenienses si se hubiesen enfrentado a los mismos desafíos. ${ }^{31}$ ¿Es esto plausible? ¿Pudieron los atenienses haber manifestado esto desde tan temprano con la suficiente credibilidad? Al fin y al cabo, antes de la guerra la reputación de Esparta tuvo que ser mucho más positiva que la de Atenas; de otra manera, a pesar del resentimiento generalizado contra ésta, sería difícil entender por qué los aliados de Esparta y la mayoría del mundo griego habrían aceptado y apoyado la intención declarada de Esparta de luchar por "la libertad de los helenos" con tanto entusiasmo y aparentemente sin sospecha alguna. ${ }^{32}$

Dado que el historiador procura, desde el comienzo, revelar que las declaraciones de Esparta constituyen propaganda, es probable que echara mano de su conocimiento posterior. Había presenciado cómo "la libertadora" (Esparta) se había transformado en un poder imperial que regía tan opresivamente como la libertadora de antaño (Atenas); por tanto, era natural que interpretara (o reinterpretara) los eventos anteriores, incluso aquellos anteriores a la guerra, desde la perspectiva posterior, la del tiempo en el que estaba escribiendo y revisando su obra. Incluso si empezó a trabajar en la Historia al principio de la guerra, el énfasis que pone en el interés propio de Esparta y su potencial imperial, aun antes de que estuviese justificado hablar de tal, probablemente es el resultado de una reescritura deliberada al servicio de su intención interpretativa. Su propósito, según sugiero, es hacer que sus lectores sepan que Esparta, movida por un "impulso imperial", ha de moverse en una dirección similar a la de Atenas antaño, y que la transformación que padeció Atenas, de hegemonía a tiranía, no era ni mucho menos única, sino que correspondía a un patrón histórico. ${ }^{33}$ En apoyo a mi propuesta podríamos fijarnos en una referencia previa a una alianza moldeada según la política de poder de su líder. En la "Arqueología”, Tucídides explica que no fue el juramento de los pretendientes de Helena (como afirmaba el relato tradicional), sino el gran poder de Agamenón y el miedo que éste producía lo que le

\footnotetext{
${ }^{31}$ Para las críticas de los aliados, especialmente 1.69.1-2 y 1.120.1. Para los embajadores atenienses, 1.75-76; cf. 1.144.2 y 5.105 .

32 Para la declaración de libertad, Th. 2.8; cf. 1.122.2-3 y 124.3. Sobre el uso y abuso de la libertad en la propaganda por parte de Esparta, véase Raaflaub 2004, pp. 193-202.
}

${ }^{33}$ Para una discusión más detallada de este patrón en concreto, véase Raaflaub 2011. 
permitieron forjar la alianza contra Troya. Al poner aquí el énfasis en conceptos como el poder y el miedo, el historiador alerta a sus lectores, ya desde el comienzo de la obra, de los factores que resultarán cruciales a lo largo de ésta. ${ }^{34}$

Encontramos una anticipación similar, y con un propósito semejante, en las Historias de Heródoto, quien también echa mano de la perspectiva posterior para interpretar la historia y moldear su narración. Describe a Esparta y Atenas como los poderes principales de Grecia ya a mediados del siglo VI, cuando el rey lidio Creso buscaba aliados en contra del rey persa Ciro. Sin embargo, en lo que sigue del relato, Heródoto no deja lugar a dudas en cuanto a que el poder de Esparta entonces era mayor que el de Atenas, la cual estaba más bien oprimida, y que ésta habría de alzarse con el poder sólo décadas después como resultado de una serie específica de eventos, que comenzó con su liberación de la tiranía, culminó con su transformación gracias a las reformas de Clístenes y que le proporcionó notables logros en el exterior. ${ }^{35}$ Como dejan claro las alusiones en las Historias a las luchas de poder en la Grecia de tiempos de Heródoto, el historiador se daba perfecta cuenta de los desarrollos posteriores cuando describía los de antaño. Sugiero, por tanto, que la anticipación que es visible en este caso en concreto está motivada por el deseo de Heródoto de alertar a sus lectores de que estos eventos corresponden a patrones (de análogos ascensos y comportamientos interesados), los cuales eventualmente causarán la rivalidad entre las dos superpotencias griegas, cuya lucha por la supremacía habría de acarrear tanta miseria a Grecia. ${ }^{36}$

No faltan más ejemplos para demostrar hasta qué punto los historiadores se apoyan en análisis a posteriori para interpretar y dar forma a la historia que ha producido este resultado, y trazar así patrones históri-

${ }^{34}$ Para Agamenón, el poder y el miedo, Th. 1.9; véase Kallet 2001, pp. 112-114, y también Vidal-Naquet 1986, pp. 46.

${ }^{35}$ Para incongruencias en el retrato de Atenas como potencia líder, Hdt. 1.56.2 y 1.59 y ss.; 5.78, y 8.3. Para paralelos en Heródoto entre el ascenso de Esparta y el de Atenas, véase Raaflaub 1988, p. 213, nota 73.

${ }^{36}$ Véase e. g. 6.98; 8.3; o 7.162.1 con una cita del mucho más tardío discurso fúnebre de Pericles (quizá en la guerra contra Samos en 440-39); véanse Munson 2001, pp. 218-219; Wees 2002, pp. 341-342, y Grethlein 2006b, pp. 498-501. Para alusiones a eventos posteriores al límite cronológico de la Historia, véase Fornara 1971a, 1981. Para otro caso de interpretación a partir de la observación posterior, véase la cita en el texto en nota 54 infra. 
$\cos .{ }^{37}$ Así, Tucídides explica desde pronto la derrota de Atenas en la guerra del Peloponeso por medio de la porfía interesada de líderes ambiciosos que no estuvieron a la altura del elevado ejemplo fijado por Pericles, el líder democrático perfecto. Desde la perspectiva de la democracia que pierde la guerra, halla su significado completo la secuencia, dramática y cuidadosamente dispuesta por el historiador, de decisiones cada vez más malas por parte de la asamblea. Las decisiones ordenadas y racionales de Pericles son sucedidas por una decisión realmente mala respecto a Mitilene, que es revocada justo a tiempo; por una decisión alocada y emotiva respecto al mando en Pilos, que debería haber conducido al desastre pero que, para sorpresa de todos, deviene en un éxito; y, finalmente, por la decisión más importante y determinante, aquella respecto a la expedición a Sicilia, decisión espoleada por la pasión (erōs), la avaricia (pleonexia) y la ambición, cuyo resultado es el desastre. ${ }^{38}$

Esta secuencia refleja el patrón según el cual el carácter colectivo ateniense se impone, cada vez de manera más perniciosa. El retrato ejecutado en el discurso fúnebre de la comunidad-ciudadano se ve inmediatamente en entredicho por el impacto de la peste y es deteriorado aún más cuando los atenienses, guiados por demagogos interesados y sin escrúpulos, sucumben cada vez más al "activismo agresivo" (polypragmosynē) y a la avaricia (pleonexia). ${ }^{39}$ Las decisiones irracionales y la histeria colectiva se imponen a la razón y la moderación. Sin duda, la pintura de Tucídides carga las tintas por ambos lados: Pericles y la democracia reciben un tratamiento demasiado positivo, y los líderes tardíos y los fracasos de la democracia, demasiado negativo. Los retratos descarnados son llevados al extremo por la disminución del análisis detallado, por parte del historiador, a unos pocos episodios cruciales y el enfoque en unos pocos aspectos esenciales. ${ }^{40}$ Pero es que se trata precisamente de

${ }^{37}$ Incluso si Tucídides se empeña por describir la historia como no finalizada (Grethlein 2009, pp. 164-171).

${ }^{38}$ Para los líderes, véase 2.65. Sobre la secuencia de decisions en deterioro, véanse 3.36-49 (Mitilene); 4.27-28 (cf. 4.15-22 y 27.41: Pilos); y 6.8-26 (en especial 15.19.24: Sicilia).

${ }^{39}$ Para polypragmosyne (1.70), véase Raaflaub 1994; 2006, pp. 198-209.

${ }^{40}$ Fueron muchísimas las críticas a Pericles, especialmente en sus años finales, por su decisión de declararle la guerra a Esparta, hasta el punto de que se lo comparó a un tirano (Podlecki 1998, pp. 169-76; y Jordović 2005, pp. 135-139). Sobre los errores en la valoración de Pericles por parte de Tucídides, véase e. g. Hornblower 1991-2008: 
eso: la disposición en patrones requiere pinceladas gruesas, líneas expresivas y contrastes, y simplificación; la disposición en patrones contiene y a la vez requiere elementos de ficción. ${ }^{41}$

Así que volvemos a la pregunta de por qué la disposición en patrones era útil, aun necesaria. Jonas Grethlein observa que "el presupuesto subyacente de patrones regulares era un modo de sobreponerse a la arbitrariedad del azar, que era percibido como una fuerza amenazante". ${ }^{42}$ Como comprobamos antes, concentrarse en aspectos específicos de la disposición en patrones le permitía al historiador organizar el material según líneas específicas, y así agilizar su esfuerzo por extraer un significado. O sea, apuntalaba su propósito didáctico. ${ }^{43}$ La relación entre pasado y presente, en la historia lo mismo que en la tragedia, es interactiva: la preocupación del historiador por los problemas de su propio tiempo lo lleva a percibir y comprender los eventos históricos de determinada manera; su interpretación de tales eventos, a su vez, influye, incluso moldea, la manera en que los describe. Su objetivo es poner énfasis sobre las cuestiones cruciales, inducir a los lectores a reconocerlas como tales y a conectarlas con el presente, a estimular sus mentes y a que adquieran una conciencia crítica. Pero, igual que el tragediógrafo, el historiador no le regala al lector las lecciones ya procesadas, sino que tiene que derivarlas por su propia cuenta.

La pregunta, por consiguiente, es: ¿por qué tanto Heródoto como Tucídides atribuyen tanta importancia al propósito didáctico de la historia?

I.342-343 respecto a Th. 2.65.5; sobre los errores en la valoración de los sucesores de Pericles, ibid. 340-341, 346-347. Para Tucídides y la democracia, véanse Farrar 1988, cap. 5; Pope 1988; Ober 1998, cap. 2; Leppin 1999, y Raaflaub 2006.

${ }^{41}$ Patrones semejantes se encuentran en los aspectos centrales de la interpretación de la historia por parte de Tucídides, sobre todo en su análisis de la guerra frente a la paz, o el imperialismo frente a la libertad. Para un breve tratamiento de la guerra y la paz, véanse Raaflaub 2007 y -de manera más general - 2009. Para el imperialismo y la libertad, de Romilly 1963 y Tamiolaki 2010.

${ }^{42}$ Grethlein 2006b, p. 502.

${ }^{43}$ Las lecciones derivadas de estos patrones, según sugiero, no son lo mismo que los "modelos" que ofrece Tito Livio en su "historia ejemplar" (pref. 9-10; véanse Chaplin 2000 y Mehl de próxima aparición). Los exempla invitan o bien a la imitación directa o bien a ser evitados, por lo que tienen que ver primordialmente con actitudes morales y principios de comportamiento, mientras que los patrones suscitan el pensamiento crítico y tienen que ver sobre todo con cuestiones políticas. Para una discusión general, véase Grethlein 2006a, pp. 32-40, en especial 34. 
¿Por qué no les basta con narrar la historia? ¿Por qué necesitan dotarla de sentido para el público? Una respuesta es que ciertamente el pasado estaba ya "funcionalizado" de tal manera por modelos poéticos como el de Homero, la poesía lírica y elegíaca, llegando hasta la tragedia. Otra respuesta más importante que quisiera sugerir es que en la época de estos historiadores el pasado no era tenido por interesante en sí mismo: los griegos ni tenían museos ni enseñaban historia en sus escuelas como materia autónoma; su cultura no promovía, como sí lo hace la nuestra, un interés integral y casi automático por la historia en sí misma, aun cuando, de distintas maneras, casi todos los géneros de la literatura griega incluyeran reflexiones sobre el pasado. ${ }^{44}$ Bien fuera histórico, bien mítico, el pasado despertaba interés por lo etiológico o sensacional, porque resultaba relevante para determinadas personas, grupos o comunidades a la hora de conformar o confirmar sus identidades, o porque proporcionaba un conjunto de relatos familiares que podían ser adaptados y empleados para fines varios. ${ }^{45}$

Ahora bien, resulta sensato asentar que en general el pasado era recordado en tanto fuese relevante, normalmente para audiencias específicas. Si los recuerdos perdían su relevancia, se desvanecían o se transmutaban radicalmente. Al final, incluso eventos importantes corrían el riesgo de

44 Para modelos poéticos, supra nota 15; también véanse los capítulos de Jonas Grethlein y Ewen Bowie en Konstan y Raaflaub 2010. Para la ubicuidad de las referencias históricas, véase Grethlein 2010, pp. 2-3 con bibliografía (incluyendo sobre todo a van Groningen 1953). Para la información histórica recogida (no menos por Heródoto o Pausanias) de ofrendas votivas en santuarios griegos, véanse e. g. Habicht 1985: cap. 3-4; y Flower 1991; cf. etiam Higbie 2003 (sobre la Crónica Lindiana, inscrita en 99 a. C., que preserva un registro de las ofrendas votivas a la Atenea Lindia en Rodas); y Kreutz 2004 (sobre Olimpia). Pero las colecciones de tales ofrendas no eran el resultado de un esfuerzo consciente por conmemorar el pasado de manera coherente, sino que eran el resultado accidental de la generosidad de los fieles de una deidad o premeditado por parte de intereses políticos en juego (véase Yates 2009 para los monumentos de las guerras médicas en Delfos). El interés por su sentido histórico siguió al desarrollo de la historia como objeto de estudio y género literario.

45 Un raro testimonio del "interés histórico" es iluminador: los espartanos, dice el sofista Hipias en el Hipias mayor (285d), "disfrutan con las genealogías de sus héroes y hombres, y con las historias sobre la fundación de ciudades de tiempos remotos y, por decirlo brevemente, con todo tipo de antigüedades" (pasēs tēs archaiologias): esencialmente, pues, de aquello de lo que cantaba la poesía épica y parte de la elegíaca (sobre ésta, véanse Bowie 2010 y Boedeker 2011). Le agradezco a David Sider la referencia a Hipias. 
ser sustituidos por otros posteriores más importantes. Es cierto que los objetos de las obras de nuestros dos historiadores, las guerras médicas y la del Peloponeso, no estaban en peligro de ser olvidadas dado que ambas habían tenido un impacto decisivo en acontecimientos posteriores y habían afectado la historia y la identidad de las partes involucradas. Pero no sólo se tendía a recordar acontecimientos distintos, sino que incluso los acontecimientos principales eran recordados de manera diferente por parte de quienes los habían presenciado. El conjunto de elementos comunes entre los diversos recuerdos era más bien reducido, limitado de hecho a un esquema básico. David Yates ha demostrado esto con lucidez respecto a las guerras médicas. ${ }^{46}$ Lo mismo vale para la guerra del Peloponeso.

Esforzándose por dejar atrás estos recuerdos locales, Heródoto retoma la altura de miras de la Ilíada e interpreta las guerras médicas no desde el partidismo de cada polis, sino desde la perspectiva general, la panhelénica, por no decir la humana. De tal manera, Heródoto insiste en que su objetivo es prevenir que los "logros humanos" caigan en el olvido con el paso de los años, y que "los hechos grandes y asombrosos" de griegos y no griegos pierdan su gloria (kleos), sobre todo el hecho más grande y asombroso de todos, la guerra entre griegos y persas. La alusión a la "gloria inmarcesible" (kleos aphthiton) prometida al cantor épico, y el esmero del autor por justificar su cometido por medio de la grandeza y la relevancia de lo narrado, resultan obvios. Sin embargo, Heródoto tuvo que escoger entre tradiciones orales diferentes y a veces tuvo que ir contra la corriente de la opinión popular. ${ }^{47}$ Para entonces, Grecia estaba gravemente fragmentada: se insistía, en ocasiones de manera destructiva, en las diferencias étnicas, culturales y políticas. El público panhelénico que Heródoto buscaba existía sólo de formas muy limitadas: para ciertos tipos de poesía y oratoria, y en los certámenes en las fiestas panhelénicas. Tuvo que crear el público

46 Sobre la memoria fragmentada, Yates 2009; véanse también Jung 2006 y Bridges et al. 2007. Para la discusión sobre la "memoria cultural", véanse e. g. Assmann 1997; Assmann y Hölscher 1988; y de manera más general, e. g. Vansina 1985; UngernSternberg y Reinau 1988, y Thomas 1989.

${ }^{47}$ Sobre la perspectiva panhelénica de la épica y la poesía griega temprana, véanse Nagy 1990 y 1999. Sobre la "perspectiva humana" (griegos y bárbaros): Heródoto, "Prefacio". Sobre la gloria y la grandeza, Hdt., "Prefacio"; y 7.20. Para la elección entre tradiciones distintas, Lateiner 1989, pp. 84-90; para la contradicción de opiniones populares, Hdt. 7.139. 
de la historia. El interés por sus logoi no fue automático, sino que hubo de ser estimulado mediante el énfasis en aspectos que resultasen importantes no sólo para cada polis por separado sino para todas en conjunto. Por estas razones, la disposición en patrones devino crucial para Heródoto: se centraba precisamente en los aspectos de importancia universal.

Tucídides también escribe desde una posición independiente, insistiendo en que su exilio le permitió ver "lo que hacían ambos bandos", y que él también anhela que su obra sea de interés "a quienes quieran saber con certeza" qué pasó. Empero va más allá de sus antecesores y demuestra de manera bien elaborada que la guerra que describe fue de hecho la mayor guerra de todas. Suma a esta afirmación otra: que redacta una obra que será útil para siempre, e incluso deja que Pericles exalte el valor de los logros que resultarán de esta gloria de recuerdo perpetuo. ${ }^{48}$ Más aún, si bien la noción de ktēma es aiei se asemeja a aquella otra homérica de kleos aphthiton, Tucídides reclama la eternidad no por su tema sino por los lectores que tendrá, reemplazando la fama con la utilidad. La historia combina de este modo la preservación de la memoria de los grandes hechos, sobre todo de los más grandes hechos en absoluto (las grandes guerras), con la prueba de su relevancia y de su uso por parte de audiencias presentes y futuras. ${ }^{49}$

Como he apuntado en otro lugar, todo esto se diferencia bastante de las premisas modernas al abordar la historia, y nos parece complicado derivar todas las consecuencias a partir de nuestro entendimiento y nuestro uso de la historiografía y la historia antiguas. En últimas, en el caso de Heródoto no nos queda más que perder una parte nada desdeñable de lo que pensamos que fue la historia griega arcaica, por lo menos antes del umbral que representa la mitad del siglo VI, y parece que esto no es más que una pequeña compensación por lo mucho que ganamos en cuanto a entendimiento profundo de las condiciones, corrientes intelectuales y mentalidades de tiempos de Heródoto. ${ }^{50}$ En apariencia, el caso de Tucídides se presenta como - hasta cierto punto- distinto: el

48 Para la posición independiente, Th. 5.26.5; véase 1.1.1; y Boedeker 1998. Para el conocimiento preciso, 1.22.4. Para la demostración de la grandeza de la guerra, 1.1-19; para la gloria de perpetuo recuerdo (doxa aieimnēstos), 2.64.5. Cf. etiam Hdt. 6.109.3 con Th. 2.41.4 y 64.3 .

49 Sobre el "rescate de lo notable del olvido", véase Dewald 2007, pp. 91-94. Sobre el reemplazo de la fama por la utilidad, Crane 1996, p. 215, y Grethlein 2010, p. 214.

${ }^{50}$ Raaflaub 2010b, p. 203. 
tema de su Historia es contemporáneo, y su esfuerzo por explicar los principios inspira más confianza en su "profesionalismo" como historiador. Y sin embargo es Tucídides quien declara de manera explícita su empeño por hacer útil a la historia en todo momento, y precisamente en este punto hubo de enfrentarse a los mismos retos que afrontó Heródoto. Propongo que su necesidad por elaborar, enfatizar la interpretación y por tanto "manipular" la historia no fue menos urgente. Al minar el "potencial provechoso" de la historia, Tucídides se zambulle en la tarea de aislar los patrones de los que hemos hablado. Lo hace ciertamente en sus discursos, y quizá también en su narración, pero esto es más difícil de demostrar. ${ }^{51}$ Pues tras formular su metodología en los capítulos más famosos, nos ofrece una narración densa y compleja, y sin embargo fluida, la cual revela los resultados de su análisis y reconstrucción sin revelar el proceso por el que llegó a ellos. Mas no faltan la exageración, la manipulación y hasta la invención; he mencionado algunas instancias. Uno de los retos al trabajo futuro sobre este historiador será precisamente la detección y elucidación de estos esfuerzos por disponer en patrones.

Como dije anteriormente, a pesar de sus diferencias en edad, Heródoto y Tucídides fueron contemporáneos. Echaron mano de la misma fuente común de ideas y teorías que empapaban las discusiones intelectuales de su tiempo, y reaccionaron a los mismos eventos y a las mismas corrientes. Tucídides también respondió a la obra de Heródoto. ${ }^{52}$ Los trabajos de ambos se diferencian enormemente en muchos aspectos, pero también comparten varias correspondencias sorprendentes en sus respuestas a los grandes desafíos que presentaba la nueva tarea que emprendieron. La disposición en patrones es una de ellas. Paso ahora a describir, siquiera con brevedad, otras correspondencias.

Ambos autores estaban motivados por un potente deseo por desenmascarar la propaganda política y desideologizar la historia. Este esfuerzo, centrado sobre todo en los usos y abusos de la libertad, resulta obvio en Tucídides, y con razón, ya que escribía sobre una guerra en la

${ }^{51}$ Sobre la forma que Tucídides le da a la historia, Rood 1998; Greenwood 2006; también Hunter 1973 (Tucídides como informador artificioso); Badian 1993 (informador engañoso).

52 Sobre el ambiente intelectual compartido, supra nota 20. Sobre la respuesta de Tucídides a Heródoto, e. g. Hornblower 1987, pp. 13-33; 1991-2008, II, pp. 19-38, 122145; Moles 1993; Rood 1999; Rogkotis 2006, y Rengakos 2006. 
que luchó bajo el signo de la libertad desde ambos bandos.$^{53}$ Heródoto, escribiendo sobre la guerra que sin duda preservó la libertad de los helenos, tenía pocos motivos para criticar la empresa en sí. Sin embargo, de manera inequívoca, si bien indirecta, confuta particularmente las consignas que los atenienses acuñaron posteriormente. Lo hace al defender resueltamente los méritos atenienses en las guerras médicas y dándoles espacio para presentar sus ideales en palabras que de manera implícita mas luminosa dejan en evidencia la contradicción entre políticas y comportamiento de antaño y de hogaño. ${ }^{54}$

El caso de la "autosuficiencia" (autarkeia) es igualmente interesante. En el discurso fúnebre, Tucídides permite a Pericles insistir en que Atenas en esa época era "completamente autosuficiente tanto en la paz como en la guerra", y que cada ciudadano, "en todos los variados aspectos de la vida, era capaz de mostrarse como una persona autosuficiente (sōma autarkes)". Esta afirmación era parte de la "ideología de la libertad" ateniense, y probablemente es auténtica. ${ }^{55}$ Es una afirmación digna de nota. ¿Cómo es que puede ser verdadera? Al fin y al cabo, la mayor parte de autores antiguos coinciden en que la autosuficiencia es un ideal inalcanzable para los seres humanos comunes y corrientes. Incluso una comunidad depende de otras para satisfacer sus necesidades. Aun así, según Pericles, los atenienses han trascendido tales limitaciones de dos maneras. Una es que la comunidad provee al ciudadano con las condiciones necesarias para el desarrollo de la virtud versátil e independiente, para convertirse en una persona autosuficiente (sōma autarkes) ${ }^{56}$

${ }^{53}$ Sobre la libertad como propaganda en ambos bandos: Raaflaub 2004, cap. 5.

${ }^{54}$ Hdt. 7.139; 8.140-44. Sobre la insistencia de Heródoto sobre las guerras médicas como esfuerzo por preservar la libertad griega, véase von Fritz 1965; 1967, esp. 266 y ss.

55 Th. 2.36 (polis autarkestatē). Para la autosuficiencia (autarkeia) como concepto politico, Raaflaub 2004, pp. 184-187 (con fuentes). Para la ideología ateniense de la libertad, ibid. pp. 181-93. Para la autosuficiencia individual, Th. 2.41 (Pericles): "Declaro que en mi opinión cada uno de nuestros ciudadanos, en los varios aspectos de la vida, es capaz de mostrarse como una persona autosuficiente (sōma autarkes) y hacer esto, de hecho, con excepcional gracia y versatilidad".

${ }^{56}$ La idea de la polis como condición indispensable para el logro individual y la virtud permean todo el discurso. Esto también tiene un paralelo en la insistencia de Heródoto en que la capacidad del ciudadano individual de alcanzar la máxima valentía en el campo de batalla se debe exclusivamente a que las leyes superiores de Esparta estrechan los lazos comunitarios dentro de la polis; véanse Dihle 1981, pp. 59-63 y Lateiner 1989, pp. 160-161. 
Como comunidad, por su parte, Atenas depende de un ente más grande: el mundo exterior, incluso allende su imperio. Pero aun así es autosuficiente porque tiene el poder necesario para garantizar que todas sus necesidades serán satisfechas permanentemente. De este modo, Pericles emplea el concepto de autosuficiencia total como manera triunfal de caracterizar la capacidad extraordinaria que su ciudad ha alcanzado.

Ambos historiadores, empero, se negaron a aceptar esta afirmación. Tucídides, en su propia voz, observa en su relato de la gran peste que ninguna persona autosuficiente (sōma autarkes) asomó por ahí. La peste, yuxtapuesta al discurso fúnebre con el elogio de Pericles a la Atenas democrática como comunidad ideal, pone en solfa la vacuidad del ideal. Ante la terrible crisis, la pátina de buena ciudadanía se desmorona y el animal humano luce en toda su crudeza. ${ }^{57}$ En la respuesta que el sabio Solón le da al hombre más rico del mundo - el rey lidio Creso-, Heródoto señala que "Nadie puede acumular todas las ventajas, así como un país no puede producir todo lo que necesita [...]. El mejor país es el que tiene más. Así es con la gente: ninguna persona es autosuficiente; siempre hay algo que le falta. Pero quien tenga el mayor número de cosas buenas $[\ldots]$ y las conserve hasta el final, y muera una muerte en paz, ese hombre [...] merece ser llamado dichoso". ${ }^{58}$ Ambos historiadores, por consiguiente, confutan categóricamente la ideología, sea en política o en historia.

Otro caso de pensamiento paralelo entre ambos historiadores tiene que ver con el problema de cómo abordar una serie de eventos parecidos y de importancia parecida: ¿acaso deben recibir la misma atención y detalle? Si no, ¿qué criterios han de emplearse para escoger entre ellos? Con frecuencia, Tucídides opta por un tratamiento a fondo del primer acontecimiento de una clase en toda la guerra (como en el caso de Córcira para conflictos intestinos destructivos, o stasis, o el de Mitilene para la revuelta de un aliado de Atenas y de su sofocación), seguido si acaso de una breve mención de subsiguientes acontecimientos de su clase. ${ }^{59}$

\footnotetext{
${ }^{57}$ Para la confutación de Tucídides de la afirmación de Pericles, 2.51 (en la descripción de la peste): "En verdad ninguna constitución física era suficiente para resistir la enfermedad" (literalmente: "no había ninguna persona o cuerpo autosuficiente, ninguna sōma autarkes").

${ }^{58}$ Hdt. 1.32.

${ }^{59}$ Para Córcira, 3.69-85; para Mitilene, 3.2-50.
} 
Pero en un caso, Tucídides optó por otra solución. Aunque la primera expedición a Sicilia de 427-424 no fue mucho menos insignificante y puso al descubierto las intenciones manilargas de Atenas, procuró dividir su relación de este hecho en una serie de segmentos a lo largo de varios años, e incluyó sólo un discurso importante. La razón parece obvia: el historiador no quería socavar su propio terreno. La segunda, la "gran" expedición a Sicilia recibe un tratamiento muy especial y forma prácticamente su propio libro dentro de la obra, el cual se abre con su propia introducción y serie elaborada de discursos, empezando con la gloriosa partida de la armada ateniense y acabando con la trágica destrucción de la fuerza expedicionaria. ${ }^{60}$

No podemos más que acordarnos de la descripción de Heródoto del grandioso comienzo y el patético final de la expedición de Jerjes. Más aún, la opción de Tucídides de centrarse en la gran expedición halla una correspondencia cercana en Heródoto. El relato de éste sobre la campaña de Maratón resulta insuficiente, una decepcionante reconstrucción de la batalla. ${ }^{61}$ Apenas podemos entender la estrategia de Milcíades, pero las actuaciones griegas quedan aisladas de los planes y actuaciones persas, sobre las cuales no oímos prácticamente nada. Tales opiniones son más patentes si comparamos esta relación con la descripción detallada de Heródoto de otra batalla en tierra, la de Platea. Ahí sí presta atención a las consideraciones complejas y a las maniobras de ambos bandos, por separado y mutuamente. Claramente, ahí sí emplea información aportada por los dos bandos. La explicación tradicional - que por una distorsión política e ideológica tanto a nivel familiar como a nivel de polis, Heródoto no fue capaz de hallar información detallada respecto a batallas posteriores - parece convincente hasta cierto punto. Más bien, considero que Heródoto decidió no escribir un relato más completo porque Maratón no ofrecía el tipo de iluminaciones históricas que esperaba proporcionar. En su obra, esta batalla culmina una línea de desarrollo que atrae la atención de los persas hacia Atenas, despierta su ira y hace de Atenas el blanco de una expedición punitiva. Maratón es esencialmente

${ }^{60}$ Para la gran expedición a Sicilia, Th. 6.1-8.1. Para la primera, 3.86, 88, 90, 99, 103, 115; 4.1-2, 24-25, 48, y 6.58-65; véase también 5.4. Para el discurso de Hermócrates, 4.58-65. Para la discusión, véase Raaflaub 2002a, pp. 29-32 (con bibliografía).

${ }^{61}$ Hdt. 6.102-17. Para un tratamiento más completo del argumento que aquí hago, véase Raaflaub 2010a. 
una victoria ateniense que salva a Atenas de la venganza persa y que, por consiguiente, es una condición crucial para el eventual ascenso de Atenas al poder. Desde el punto de vista de Heródoto, panhelénico y no ateniense, lo más importante de la guerra contra Jerjes es que es una guerra por la libertad griega. ${ }^{62}$

Esta opción narrativa está reflejada en la estructura de la obra. El relato sobre Darío en la tríada intermedia (libros IV-VI), que acaba con el Maratón, conforma el preludio a la guerra greco-persa de la última tríada (VII-IX), la de el ascenso y caída de la gran expedición de Jerjes, la cual representa el enfrentamiento de dos mundos distintos, de sistemas sociopolíticos en claro contraste, de ideologías y sistemas de valores incompatibles, de dos maneras irreconciliables de hacer la guerra. El libro VII se abre, pues, con un nuevo comienzo que esclarece, en un detalle sin precedentes y con varios discursos, el proceso de decisión en la corte de Jerjes y que introduce una nueva narración. El entendimiento por parte de Heródoto de la formidable importancia de la campaña de Jerjes, tanto por sí misma como por la manera en que estableció la relevancia de la historia del pasado en su propio tiempo y mucho después, marcó la manera en que dispuso las Historias. Una vez decidió que esta campaña iba a ser el plato fuerte de la obra, no tuvo sentido anticiparse demasiado y narrar con mucho detalle la campaña anterior, más pequeña y modesta, de Datis y Artafernes contra Atenas. A pesar de Maratón.

Las correspondencias entre las decisiones de los dos historiadores a la hora de organizar sus narraciones son obvias. De hecho, las correspondencias entre el debate en la corte de Jerjes en Heródoto y el debate siciliano en Tucídides son lo suficientemente numerosas y específicas como para sugerir una compleja relación entre los propios debates, las obras maestras narrativas que preceden y los autores que las concibieron. ${ }^{63}$ Esto trae a colación las correspondencias más generales en el uso de los discursos. Por supuesto que la incorporación de discursos es parte de la emulación de Homero por parte de los historiadores. Pero van más allá del aprovechamiento homérico de los discursos: aumentan la inmediatez

62 Para Atenas y Persia en los libros de Darío, en especial 5.73, 96-97, 99-102, 105; 6.43-44, 48-49, 94; véase también 8.142.2. Para la importancia de Maratón en el ascenso de Atenas al poder, 6.109. Para la relevancia panhelénica de la expedición de Jerjes, en especial 7.139; cf. 8.140-44.

${ }^{63}$ Para una exploración detallada de esta relación, véase Raaflaub 2002a. 
narrativa y los efectos narrativos, y tanto en Heródoto como en Tucídides, muchos discursos cumplen una función interpretativa crucial en cuanto a elucidar las causas, los motivos y los principios. Esta cuestión ha recibido un tratamiento intenso y controversial en cuanto a Tucídides; merece una atención más comprensiva y cuidadosa en cuanto a Heródoto. ${ }^{64}$

También valdría la pena discutir en detalle las correspondencias entre los dos autores respecto al empleo deliberado y abundante de la mirada retrospectiva para reinterpretar la historia (discutida arriba), y en la naturaleza programática de sus libros inaugurales: en ambos casos, una sección en concreto al comienzo (el logos de Creso en Heródoto y la "Arqueología" en Tucídides) subraya una selección de temas especialmente importantes que hallarán ecos por toda la obra. ${ }^{65}$ Un propósito programático similar es detectable en los más tempranos discursos tipificados, cuyos temas reaparecen en pasajes importantes. La recurrencia en sí ayuda a elucidar cuál es la interpretación que se espera de ellos y la relevancia que se les atribuye. Jonas Grethlein ha demostrado esto respecto al discurso fúnebre de Tucídides, ${ }^{66}$ y en trabajos que todavía no han sido publicados, Julia Sissa y James McGlew han propuesto cada uno por su cuenta maneras interesantes en que el debate constitucional en Heródoto insiste en aspectos cruciales que demuestran ser útiles para entender otros acontecimientos y desarrollos en las Historias.

He abordado la disposición en patrones, la desideologización, las opciones narrativas, los arreglos dramáticos en la secuencia de eventos, la función interpretativa de los discursos, el uso de la anticipación y la mirada retrospectiva, y la naturaleza programática de los libros inaugurales y los discursos tipificados. Estos aspectos iluminan las soluciones que los primeros dos historiadores dieron con el objetivo de dominar la tarea de redactar historias complejas y a gran escala. En todos estos aspectos, las correspondencias entre ambos autores resultan llamativas. Sin duda hay más. A veces todo esto me lleva a pensar que durante alguna de

${ }^{64}$ Sobre la emulación de Homero, supra nota 5. Sobre los discursos en la historiografía antigua en general, véanse Fornara 1983: cap. 4; y Marincola 2007c. En Heródoto, recientemente Pelling 2006a; en Tucídides, e. g. Stadter 1973; Hornblower 1987: cap. 3; y Morrison 2006.

65 Para el uso de la mirada retrospectiva, véase supra notas 30 y ss. Sobre el logos de Creso, véase Raaflaub 2002b: 167-74; sobre la "Arqueología" de Tucídides, Hornblower 1991-2008: I, 8 con referencia a Hunter 1982: cap. 1.

${ }^{66}$ Grethlein 2005. 
las visitas de Heródoto a Atenas, ambos se sentaron en una taberna del Ágora con sendos vasos de vino y compartieron las dificultades a las que se estaban enfrentando.

Algo más sobre la verdad histórica. Nuestros dos autores aluden a ella, los historiadores posteriores insisten en ella y Cicerón dice explícitamente que el cometido del historiador es decir la verdad y nada más que la verdad. ${ }^{67}$ ¿Cómo es esto compatible con la exageración, la invención y la manipulación que practicaron estos mismos historiadores con el objetivo de hacer útiles sus Historias? Como indica la formulación de Tucídides de "la causa más verdadera" (alēthestate prophasis), hay una verdad y luego hay una verdad más alta (o profunda). ${ }^{68}$ Considero que para los antiguos la verdad - u objetividad, que diríamos - no era una meta en sí misma. Por lo menos los más juiciosos entre ellos no estaban interesados en una verdad impersonal o desapegada, la objetividad austera. Lo que querían ofrecerle a sus lectores era, como lo formulé en otro lado, una "realidad verdadera" más profunda y una "verdad — profundamente - real"; una verdad que, por ejemplo, se hallaba oculta tras las fachadas ideológicas erigidas y por las bellas palabras pronunciadas por aquellos que detentaban el poder. ${ }^{69}$ Dejar al descubierto tal verdad sólo era posible si se sometía la historia a juicio; y los historiadores esperaban que haciéndolo, contribuirían a que sus lectores fueran más críticamente conscientes, y así los ayudasen a sobrellevar los retos de la política y la vida de su propio tiempo.

De ahí, por ejemplo, que crea desacertados los intentos de sustituir la imagen tradicional de Tucídides como informador veraz por otra de informador artificioso y aun engañoso.$^{70}$ Por supuesto que es artificioso, pues la mayor parte de los historiadores antiguos se veían a sí mismos como artistas dramáticos y literarios en la misma medida (si no más) que estudiosos. Tendríamos que ser cautos de llamarlo engañoso porque al

${ }^{67}$ Cic. De Orat. 2.62. Para la afirmación de los historiadores de establecer la verdad, véase Marincola 2007a. Para un tratamiento, véase e. g. Fornara 1983, pp. 99-120, 13741; Wheeldon 1989; Grant 1995: en especial cap. 5; Marincola 1997, pp. 158-174, en especial pp. 160-161, y los capítulos pertinentes en Gill y Wiseman 1993.

${ }^{68}$ Th. 1.23.6; véase Hornblower 1991-2008: I, pp. 64-66 con bibliografía.

${ }^{69}$ En el empeño por descubrir una verdad más profunda, Tácito es el sucesor más cercano a Tucídides; véase Raaflaub 2010b, pp. 190-94. Sobre Tácito en mayor detalle, véase Raaflaub 2008.

${ }^{70}$ Sobre lo artificioso y lo engañoso, véase supra nota 51. 
redactar su obra se atuvo a principios muy distintos a los nuestros, y los criterios con los que algunos historiadores modernos lo juzgan y pasan sentencia en su contra no eran de su conocimiento. Y claro que sí, es veraz - aun si a nuestro juicio no cuenta siempre la verdad cumplidaporque aspiraba a una verdad que viene definida por la exactitud y una comprensión completa, y lo hizo con pasión y decisión, a pesar de muchas dificultades. Sin embargo, en últimas quiso alcanzar más: transmitir una verdad más profunda que revelase en el pasado los sentidos y las lecciones que lo hacen útil al presente y al futuro, y que por sí solos son capaces de convertir la historia en "una posesión para siempre". De varias maneras, creo que también éste era el propósito de Heródoto. ${ }^{71}$ Pero nuestra comprensión de este cometido, en sus muchas dimensiones y consecuencias, dista todavía bastante de ser completo.

\section{BIBLIOGRAFÍA}

Asheri, D., A. Lloyd y A. Corcella, A Commentary on Herodotus Books I-IV, Oswyn Murray y Alfonso Moreno (eds.), Oxford, Oxford University Press, 2007.

Assmann, J., Das kulturelle Gedächtnis. Schrift, Erinnerung und politische Identität in frühen Hochkulturen, München, C. H. Beck, 1997.

_ $\quad$ y T. Hölscher (eds.), Kultur und Gedächtnis, Frankfurt, Suhrkamp, 1988.

- y K. E. Müller (eds.), Der Ursprung der Geschichte. Archaische Kulturen, das Alte Ägypten und das Frühe Griechenland, Stuttgart, Klett-Cotta, 2005.

BADIAN, E., "Thucydides and the Outbreak of the Peloponnesian War: A Historian's Brief", From Plataea to Potidaea: Studies in the History and Historiography of the Pentecontaetia, Baltimore, The Johns Hopkins University Press, 1993, pp. 125-162.

BAKKeR, E. J., I. J. F. De Jong y H. van Wees (eds.), Brill's Companion to Herodotus, Leiden, Brill, 2002.

Boedeker, D. (ed.), Herodotus and the Invention of History. Arethusa, 20, 1987.

_, "Presenting the Past in Fifth-Century Athens", en Boedeker y Raaflaub, 1998, pp. 185-202, 387-92.

_, "Epic Heritage and Mythical Patterns in Herodotus", en Bakker et al. 2002, pp. 97-116.

_, "Early Greek Poetry as/and History", en A. Feldherr y G. Hardy (eds.), The Oxford History of Historical Writing, Oxford, Oxford University Press, 2011, pp. 122-147.

${ }^{71}$ Mucho se podría aprender de todo esto, e. g. de Fornara 1971b, 1983; Marincola 1977; o Dewald 2007. 
BoEDEKER, D. y K. Raaflaub (eds.), Democracy, Empire, and the Arts in FifthCentury Atenas, Cambridge, Mass., Harvard University Press, 1998.

_ y K. Raaflaub, "Tragedy and City", en R. Bushnell (ed.), A Companion to Tragedy, Malden, Mass. / Oxford, Blackwell, 2005.

BowIE, E., "Historical Narrative in Archaic and Early Classical Greek Elegy", en Konstan y Raaflaub, 2010, pp. 145-166.

Bridges, E., E. Hall y P. J. Rhodes (eds.), Cultural Responses to the Persian Wars, Oxford, Oxford University Press, 2007.

CANFora, L., "Biographical Obscurities and Problems of Composition", en Rengakos y Tsakmakis, 2006, pp. 3-31.

Cartledge, P., Agesilaos and the Crisis of Sparta, Baltimore, The Johns Hopkins University Press, 1987.

Chaplin, J., Livy's Exemplary History, Oxford, Oxford University Press, 2000.

Corcella, A., "The New Genre and Its Boundaries: Poets and Logographers", en Rengakos y Tsakmakis, 2006, pp. 33-56.

Crane, G.. The Blinded Eye: Thucydides and the New Written Word, Lanham, Rowman \& Littlefield, 1996.

Darbo-Peschanski, C., "The Origin of Greek Historiography", en Marincola 2007b, pp. 27-38.

Derow, P., "Why Ancient History?", en A. Erskine (ed.), A Companion to Ancient History, 3-5, Malden, Mass. / Oxford, Wiley-Blackwell, 2009, pp. 3-5.

Dewald, C., "Practical Knowledge and the Historian's Role in Herodotus and Thucydides", en Jamerson, M. H. (ed.), The Greek Historians: Literature and History. Papers Presented to A. E. Raubitschek, Stanford, Anma Libri, 1985, pp. 47-63.

_, "Wanton Kings, Pickled Heroes, and Gnomic Founding Fathers: Strategies of Meaning at the End of Herodotus's Histories", en D. H. Roberts, F. M. Dunn y Don Fowler (eds.), Classical Closure: Reading the End in Greek and Latin Literature, Princeton, Princeton University Press, 1997, pp. 62-82.

_, "Form and Content: The Question of Tyranny in Herodotus", en K. Morgan (ed.), Popular Tyranny: Sovereignty and Its Discontents in Ancient Greece, Austin, University of Texas Press, 2003, pp. 25-58.

_, Thucydides' War Narrative: A Structural Study, Berkeley, University of California Press, 2005.

- y J. Marincola (eds.), The Cambridge Companion to Herodotus, Cambridge, Cambridge University Press, 2006.

_, "The Construction of Meaning in the First Three Historians", en Marincola 2007, vol. I, pp. 89-101.

Dirle, Albrecht, "Die Verschiedenheit der Sitten als Argument ethischer Theorie", en G. E. B. Kerferd (ed.), The Sophists and their Legacy, Wiesbaden, Franz Steiner (Hermes Einzelschrifen, 44), 1981, pp. 54-63.

DurRant, S., "The Task and Ritual of Historical Writing in Ancient China", en K. Raaflaub (ed.), Thinking, Recording, and Writing History in the Ancient World, Malden, Mass. / Oxford, Wiley-Blackwell, 2014. 
Evans, J. A., "Herodotus and Atenas: The Evidence of the Encomium", en J. A. Evans (ed.), The Beginnings of History: Herodotus and the Persian Wars, Campbellville, Ontario, Edgar Kent, 2006, pp. 61-69.

FInLEY, J. H., Jr., Thucydides, Ann Arbor, University of Michigan Press, 1942.

FARrAR, C., The Origins of Democratic Thinking: The Invention of Politics in Classical Atenas, Cambridge, Cambridge University Press, 1988.

Flaig, E., "To Act with Good Advice: Greek Tragedy and the Political Sphere”, en J. Arnason, K. Raaflaub y P. Wagner (eds.), The Greek Polis and the Invention of Democracy: A Politco-cultural Transformation and Its Interpretations, Malden, Mass. / Oxford, Wiley-Blackwell, 2013.

FLORY, S., "The Death of Thucydides and the Motif of 'Land on Sea'", en Rosen y Farrell 1993, 113-123.

Flower, H. I., "Herodotus and Delphic Traditions about Croesus", en M. A. Flower y M. Toher (eds.), Georgica: Greek Studies in Honour of George Cawkwell, London, University of London, 1991, pp. 57-77.

Flower, M. y J. Marincola (eds.), Herodotus, Histories Book IX. Cambridge, Cambridge University Press, 2002.

Fornara, C. W., "Evidence for the Date of Herodotus' Publication", JHS, 91, 1971a, pp. 25-34.

_, Herodotus: An Interpretative Essay, Oxford, Oxford University Press, 1971b.

_, “Herodotus' Knowledge of the Archidamian War", Hermes, 109, 1981, pp. 14956.

_, The Nature of History in Ancient Greece and Rome, Berkeley, University of California Press, 1983.

_, “Thucydides' Birth Date”, en Rosen y Farrell 1993, pp. 71-80.

FOWLER, R., "Herodotus and His Contemporaries", JHS, 116, 1996, pp. 62-87.

_, "Herodotus and Atenas", en P. Derow y R. Parker (eds.), Herodotus and His World: Essays from a Conference in Memory of George Forrest, Oxford, Oxford University Press, 2003, pp. 305-318.

FRITZ, K. von, "Die griechische eleutheria bei Herodot", Wiener Studien, 78, 1965 , pp. 5-31.

_, Die griechische Geschichtsschreibung, I, Berlin, W. de Gruyter, 1967.

GILL, Ch., "Plato on Falsehood-not Fiction", en Gil y Wiseman 1993, pp. 38-87.

_ y T. P. Wiseman (eds.), Lies and Fiction in the Ancient World, Exeter, Devon, Uk, University of Exeter Press, 1993.

Gomme, A. W., A Historical Commentary on Thucydides, vol. I, Oxford, Clarendon Press, 1945.

GRANT, M., Greek and Roman Historians: Information and Misinformation, London, Routledge, 1995.

GreEnwoOd, E., Thucydides and the Shaping of History, London, Duckworth, 2006.

Grethlein, J., "Gefahren des logos. Thukydides' Historien und die Grabrede des Perikles", Klio, 87, 2005, pp. 41-71.

_, Das Geschichtsbild der Ilias. Eine Untersuchung aus phänomenologischer und narratologischer Perspektive, Göttingen, Vandenhoeck \& Ruprecht, 2006a. 
Grethlein, J., "The Manifold Uses of the Epic Past: The Embassy Scene in Herodotus 7.153-63", AJP, 127, 2006b, pp. 485-509.

_, “Philosophical and Structuralist Narratologies: Worlds Apart?", en J. Grethlein y A. Rengakos (eds.), Narratology and Interpretation: The Content of Narrative Form in Ancient Literature, Berlin, Walter de Gruyter, 2009, pp. 153-174.

_, The Greeks and Their Past: Poetry, Oratory and History in the Fifth Century $B C E$, Cambridge, Cambridge University Press, 2010.

Groningen, B. A. van, In the Grip of the Past: Essay on an Aspect of Greek Thought, Leiden, Brill, 1953.

Habicht, Ch., Pausanias' Guide to Ancient Greece, Berkeley, University of California Press, 1985.

Hammer, D., The Iliad as Politics: The Performance of Political Thought, Norman, University of Oklahoma Press, 2002.

Hartog, F., "The Invention of History: The Pre-History of a Concept from Homer to Herodotus", en History and Theory, 39, 2000, pp. 384-395.

Higbie, C., The Lindian Chronicle and the Greek Creation of Their Past, Oxford, Oxford University Press, 2003.

Hornblower, S., Thucydides, Baltimore, The Johns Hopkins University Press, 1987.

_, A Commentary on Thucydides, 3 vols., Oxford, Oxford University Press, 19912008.

Hunter, V. J., Thucydides the Artful Reporter, Toronto, Edgar Kent, 1973.

_, Past and Process in Herodotus and Thucydides, Princeton, Princeton University Press, 1982.

JORDOVIĆ, I., Anfänge der Jüngeren Tyrannis. Vorläufer und erste Repräsentanten von Gewaltherrschaft im späten 5. Jh. v. Chr, Frankfurt, Peter Lang, 2005.

Jung, M., Marathon und Plataiai. Zwei Perserschlachten als "lieux de mémoire" im antiken Griechenland, Göttingen, Vandenhoeck \& Ruprecht, 2006.

Kallet, L., Money and the Corrosion of Power in Thucydides: The Sicilian Expedition and Its Aftermath, Berkeley, University of California Press, 2001.

Konstan, D. y K. A. Raaflaub (eds.), Epic and History, Malden, Mass. / Oxford, Wiley-Blackwell, 2010.

KreutZ, N., "Fremdartige Kostbarkeiten oder sakraler Müll? Überlegungen zum Stellenwert orientalischer Erzeugnisse in Olympia und zum Selbstverständnis der Griechen im 7. Jh. v. Chr", en M. Novák, F. Prayon y A.-M. Wittke (eds.), Die Aussenwirkung des späthethitischen Kulturraumes, Münster, Urgait-Verlag, 2004, pp. 107-120.

Kullmann, W., "Homer and Historical Memory", en A. E. Mackay (ed.), Signs of Orality: The Oral Tradition and Its Influence in the Greek and Roman World, Leiden, Boston-Cologne, Brill, 1999, pp. 95-113.

LATEINER, D., The Historical Method of Herodotus, Toronto, University of Toronto Press, 1989.

Lendon, J. E., Song of Wrath: The Peloponnesian War Begins, New York, Basic Books, 2010. 
Leppin, H., Thukydides und die Verfassung der Polis, Berlin, Academie Verlag, 1999.

Leung, Y. S., "The Golden Past Revisited: A Reappraisal of the Views of Confucius and Mencius on History", en Chinese Culture, 23.4, 1982, pp. 65-73.

LewIS, D. M., “The Archidamian War", D. M. Lewis et al. (eds.), The Cambridge Ancient History, Cambridge, University Press, vol. V, 1992 (2ª ed.), pp. 370-432.

Marincola, J., Authority and Tradition in Ancient Historiography, Cambridge, Cambridge University Press, 1997.

_, "Herodotus and the Poetry of the Past", en Dewald y Marincola 2006, The Cambridge, Cambridge University Press, pp. 13-28.

_, "alētheia”, Lexicon historiographicum Graecum et Latinum, fasc. 2, $\alpha \lambda$ - $\alpha \phi$, diretto da C. Ampolo e U. Fantasia, coordinamento di L. Porciani [...], Pisa, Edizioni della normale, scuola normale di Pisa, 2007a, pp. 7-29.

- (ed.), A Companion to Greek and Roman Historiography, 2 vols, Malden, Mass. / Oxford, Blackwell, 2007b.

_, "Speeches in Classical Historiography", en Marincola, vol. I, pp. 118-132, 2007c.

Ment, A., "How the Romans Remembered, Recorded, Thought about, and Used Their Past", en K. Raaflaub (ed.), Thinking, Recording, and Writing History in the Ancient World, Malden, Mass. / Oxford, Wiley-Blackwell, 2014.

MeIER, Ch., "Die Entstehung der Historie", en R. Koselleck and W.-D. Stempel (eds.), Geschichte-Ereignis und Erzählung, München, 1973, pp. 251-305.

_, "Historical Answers to Historical Questions: The Origins of History in Ancient Greece”, en Boedeker, 1987, pp. 41-57.

_, The Political Art of Greek Tragedy, A. Webber (trad.), Baltimore, Johns Hopkins University Press, 1993.

Moles, J. L., "Truth and Untruth in Herodotus and Thucydides", en Gill y Wiseman, 1993, pp. 88-121.

_, "Herodotus Warns the Athenians", Papers of the Leeds International Latin Seminar, 9, 1996, pp. 259-284.

_, "Herodotus and Atenas", en Bakker et al., 2002, pp. 33-52.

Morrison, J. V., "Interaction of Speech and Narrative in Thucydides", en Rengakos y Tsakmakis, 2006, pp. 251-277.

Munson, R. V., Telling Wonders: Ethnographic and Political Discourse in the Work of Herodotus, Ann Arbor, University of Michigan Press, 2001.

Nagy, G., The Best of the Achaeans: Concepts of the Hero in Archaic Greek Poetry, Baltimore, The Johns Hopkins University Press, 1999.

_, Greek Mythology and Poetics, Ithaca, Cornell University Press, 1990.

OBER, J., “Thucydides' Criticism of Democratic Knowledge”, en R. M. Rosen y J. Farrell 1993, pp. 81-98.

_, Political Dissent in Democratic Atenas: Intellectual Critics of Popular Rule, Princeton, Princeton University Press, 1998.

_, "Thucydides and the Invention of Political Science", en Rengakos y Tsakmakis 2006, pp. 131-59. 
Ostwald, M., “Herodotus and Atenas”, Illinois Classical Studies, 16, 1991, pp. 137148.

PATZEK, B., Homer und Mykene. Mündliche Dichtung und Geschichtsschreibung, München, Oldenburg, 1992.

Pelling, Ch., "Truth and Fiction in Plutarch's Lives", en D. A. Russell (ed.), Antonine Literature, Oxford, Clarendon Press, 1990.

_, "Homer and Herodotus", en M. J. Clarke, B. G. F. Currie y R. O. A. M. Lyne (eds.), Epic Interactions: Perspectives on Homer, Virgil, and the Epic Tradition Presented to Jasper Griffin by Former Pupils, Oxford, Oxford University Press, 2006a, pp. 75-104.

_, "Speech and narrative in the Histories", en Dewald y Marincola, 2006b, pp. 103-121.

Podlecki, A. J., Perikles and His Circle, London, Routledge, 1998.

Pope, M., "Thucydides and Democracy”, Historia, 37, 1988, pp. 276-96.

PRICE, J., Thucydides and Internal War, Cambridge, Cambridge University Press, 2001.

RaAflaub, K., "Herodotus, Political Thought, and the Meaning of History", en Boedeker, 1987, pp. 221-248.

_, “Athenische Geschichte und mündliche Überlieferung”, en Ungern-Sternberg y Reinau 1988, pp. 197-225.

_, "Democracy, Power, and Imperialism in Fifth-Century Athens", en J. P. Euben, J. R. Wallach y J. Ober (eds.), Athenian Political Thought and the Reconstruction of American Democracy, Ithaca, Cornell University Press, 1994, pp. 103-143.

_, "Poets, Lawgivers, and the Beginnings of Greek Political Reflection", en Ch. Rowe y M. Schofield (eds.), The Cambridge History of Greek and Roman Political Thought, Cambridge, Cambridge University Press, 2000, pp. 23-59.

_, "Herodot und Thukydides: Persischer Imperialismus im Lichte der athenischen Sizilienpolitik", en N. Ehrhardt y L.-M. Günther (eds.), Widerstand-Anpassung-Integration: Die griechische Staatenwelt und Rom. Festschrift für Jürgen Deininger, Stuttgart, Franz Steiner, 2002a, pp 11-40.

_, "Philosophy, Science, Politics: Herodotus and the Intellectual Trends of his Time", en Bakker et al. 2002b, pp. 149-186.

_, The Discovery of Freedom in Ancient Greece, 1 ${ }^{\mathrm{a}}$. ed. rev. y trad. del alemán, Chicago, Chicago University Press, 2004.

_, "Thucydides on Democracy and Oligarchy", en Rengakos y Tsakmakis 2006, pp. 189-222.

_, "Homer and Thucydides on Peace and Just War", en M. B. Cosmopoulos (ed.), Experiencing War: Trauma and Society in Ancient Greece and Today, Chicago, Ares, 2007, pp. 81-94.

_, “The Truth about Tyranny: Tacitus and the Historian's Responsibility in Early Imperial Rome", en J. Pigoń (ed.), The Children of Herodotus: Greek and Roman Historiography and Related Genres, Cambridge, Cambridge Scholars Publishing, 2008, pp. 253-270.

_, “Conceptualizing and Theorizing Peace in Ancient Greece", TAPA, 139(2), 2009, pp. $225-250$. 
RAAFlaub, K., “Herodotus, Marathon, and the Historian's Choice”, en Kostas Buraselis y Katerina Meidani (eds.), Marathon: The Battle and the Ancient Deme, Atenas, Kardamitsa, 2010a, pp. 221-235.

_, “Ulterior Motives in Ancient Historiography: What Exactly, and Why?", en L. Foxhall, H.-J. Gehrke y N. Luraghi (eds.), Intentional History: Spinning Time in Ancient Greece, Stuttgart, Franz Steiner, 2010b, pp. 189-210.

_, "Die Versuchung der Macht. Thukydides und das Versagen hegemonialer Bundesstrukturen", en E. Baltrusch y Christian W. (eds.), Ein Besitz für Immer? Geschichte, Polis und Völkerrecht bei Thukydides, Baden-Baden, Nomos, 2011, pp. 173-194.

_, 'Ktēma es aiei: Thucydides' Concept of 'Learning through History' and Its Realization in His Work", en M. Tamiolaki y A. Tsakmakis (eds.), Thucydides' Between History and Literature, Berlin, de Grunter, 2012a, pp. 3-22.

_, "Political Thought and Literary Devices in the Early Greek Historians", Actas de las Lecturas Kaspárov, N. Grintser (ed.), Universidad Estatal de Humanidades de Moscú, en prensa.

Rawlings, H., The Structure of Thucydides' History, Princeton, Princeton University Press, 1981.

Rengakos, A., “Thucydides' Narrative: The Epic and Herodotean Heritage”, en Rengakos y Tsakmakis 2006, pp. 279-300.

- y A. Tsakmakis (eds.), Brill's Companion to Thucydides, Leiden / Boston, Brill, 2006.

Reinhold, M., "Human Nature as Cause in Ancient Historiography", en J. W. Eadie y J. Ober (eds.), The Craft of the Ancient Historian: Essays in Honor of Chester G. Starr, Lanham, University Press of America, 1985.

Rogkotis, Z., "Thucydides and Herodotus: Aspects of Their Intertextual Relationship", en Rengakos y Tsakmakis 2006, pp. 57-86.

Romilly, J. de, Thucydides and Athenian Imperialism, traducción de P. Thody, Oxford, Blackwell, 1963.

RooD, T., Thucydides: Narrative and Explanation, Oxford, Oxford University Press, 1998.

_, “Thucydides' Persian Wars", en C. S. Kraus (ed.), The Limits of Historiography: Genre and Narrator in Ancient Historical Texts, Leiden, Brill, 1999, pp. 141-168.

_, “Objectivity and Authority: Thucydides' Historical Method", en Rengakos y Tsakmakis 2006, pp. 225-49.

Rosen R. M. y J. Farrell (eds.), Nomodeiktes. Greek Studies in Honour of Martin Ostwald, Michigan, The University of michigan Press, 1993.

SAÏD, S., "Tragedy and Politics", en Boedeker y Raaflaub 1998, pp. 275-295, 410-415.

_, "Myth and Historiography", en Marincola 2007, pp. 76-88.

Ste. Croix., G. E. M. de, The Origins of the Peloponnesian War, London / Ithaca, Bristol Classical Press, 1972.

Schwartz, B., The World of Thought in Ancient China, Cambridge, Mass., Harvard University Press, 1985. 
SMITH, D. F., “Thucydides' Ignorant Athenians and the Drama of the Sicilian Expedition", Syllecta Classica, 15, 2004, pp. 33-70.

Stadter, Ph. A. (ed.), The Speeches in Thucydides, Chapel Hill, University of North Carolina Press, 1973.

Strasburger, H., "Herodot und das perikleische Athen" Historia, 4, 1955, pp. $1-25$.

_, Homer und die Geschichtsschreibung, SB Akad. Heidelberg, phil.-hist. K1. 1972.1, Wiesbaden, Carl Winter, 1972.

_, Studien zur Alten Geschichte, vol. II, W. Schmitthenner y R. Zoepffel (eds.), Hildesheim, Georg Olms, 1982.

TAMIOLAKI, M., Liberté et esclavage chez les historiens grecs classiques. Etude sur le discours historique et politique d'Hérodote, Thucydide et Xénophon, Paris, PUPS, 2010.

Thomas, R., Oral Tradition and Written Record in Classical Athens, Cambridge, Cambridge University Press, 1989.

_, Herodotus in Context: Ethnography, Science, and the Art of Persuasion, Cambridge, Cambridge University Press, 2000.

_, “The Intellectual Milieu of Herodotus", en Dewald y Marincola 2006a, pp. 6075 .

_, “Thucydides' Intellectual Milieu and the Plague", en Rengakos y Tsakmakis 2006b, pp. 87-108.

Ungern-STERnBERG, J. von y H. Reinau (eds.), Vergangenheit in mündlicher Überlieferung, Stuttgart, Teubner, 1988.

Vansina, J., Oral Tradition as History, London, James Currey Publishers, 1985.

VIDAL-NAQuet, P., "Divine Time and Human Time”, en P. Vidal-Naquet, The Black Hunter: Forms of Thought and Forms of Society in the Greek World, traducción de A. Szegedy-Maszak, Baltimore, Johns Hopkins University Press, 1986, pp. 39-60.

WeEs, H. van, "Herodotus and the Past", en Bakker et al., 2002, pp. 321-349.

Welser, Ch., "Two Didactic Strategies at the End of Herodotus' Histories (9.108122)", Classical Antiquity, 28, 2009, pp. 359-85.

WheEldon, M. J., “'True Stories': The Reception of Historiography in Antiquity”, en A. Cameron (ed.), History as Text: The Writing of Ancient History, Chapel Hill, Duckworth, 1989, pp. 33-63.

YAtes, D., Remembering the Persian War Differently, Rhode Island, Brown University, 2009. 
